\title{
Media neutral planning - A strategic perspective
}

Received: 28th April, 2004

\begin{abstract}
Alan Tapp
is Senior Lecturer in Marketing at Bristol Business School. Alan has published over 35 articles in leading journals and international conferences as well as a best-selling textbook. Much of his research has been sponsored by organisations, for example IBM, Christian Dior and The Chartered Institute of Marketing. He is on the Editorial Board of the Journal of Database Marketing \& Customer Strategy Management. He has undertaken research, consultancy and training for organisations as diverse as the NSPCC, The Institute of Direct Marketing, National Centre for Educational Technology, Business Strategies Ltd, The Royal Mail (now Consignia), The CIM, IBM and Coventry City Football Club. He is the author of 'Principles of Direct and Database Marketing', now in its second edition.
\end{abstract}

\begin{abstract}
The last year or two has seen media neutral planning emerge as the 'hottest new thing'. There has been little published, however, that explains to practitioners how to assess direct marketing media objectively. This paper introduces a simple-to-use framework, AIMRITE, that takes managers methodically through a series of steps that they need to take in order to create a short list of direct response media to test. An example is created to illustrate how this might work in practice.
\end{abstract}

\section{MEDIA NEUTRAL PLANNING: WHY THE EXCITEMENT?}

One thing that hits home listening to sales pitches by marketing consultants and gurus is the way in which, so often, the wheel is re-invented or old wine is presented in new skins. 'Media neutral planning' (MNP) is perhaps one of the most extreme examples of this in recent times. If the sense of the phrase is taken at face value then surely nothing could be more obvious. If the logic is reversed for a second, however, the alternative is 'biased to my favourite media planning'. So why has the Chartered Institute of Marketing (CIM) decided that: 'The CIM is focusing one of its major Canons of Knowledge on

Alan Tapp

Senior Lecturer, Bristol Business School, University of the West of England, Frenchay Campus, Coldharbour Lane, Bristol, BS16 1QY, UK.

Tel: +44(0) 1173443439 e-mail:

Alan.Tapp@uwe.ac.uk media neutral planning: almost certainly the most important new idea for change across the marketing communications industry at the moment?'

Clarification dawns when one takes a look at what the players in the MNP arena have to say. Here's IBM.
'MNP de-silos the communications process, enabling previously competing departments to work together and stops departments fulfilling their own objectives without knowing the overall objectives of the company and of the particular campaign. "That's a change for many people in marketing. Most have been brought up with advertising, direct marketing, running events, and so forth. We have to realise that $x$ is a medium we need to include - and maybe $y$ is the one we need to concentrate on first because it has the most impact" March 2004). ${ }^{2}$

Other players in MNP include communications consultants Naked and Nylon which says

'Naked does media planning. It advises clients on the best media approach to take in order to achieve brand objectives. But unlike most media planners, they offer an unbiased approach to media. "We don't have a large creative factory that needs feeding, so we are able to be neutral in the advice we offer...We 


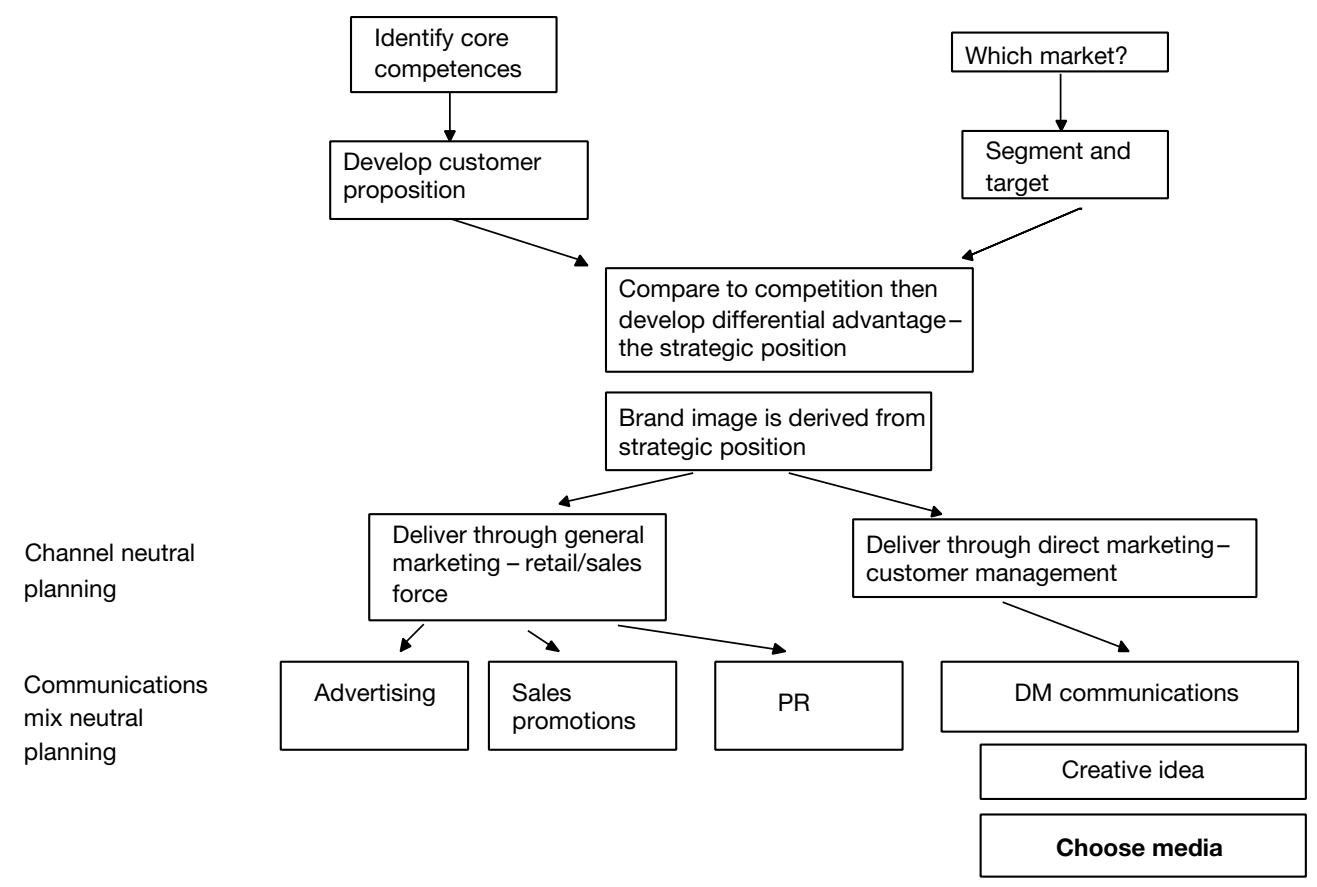

Figure 1: Media neutral planning

don't make anything, so we're not tied to one approach. If you go to an advertising agency, they will tell you why you need advertising. We are free of that obligation, which is what appeals to clients. We might suggest advertising, but equally we might suggest some TV content or viral marketing. ${ }^{3}$

Meanwhile the Interactive Advertising Board says: 'It's simply about getting the balance right. That's the theory in the media-neutral planning world and the massive rise in internet audiences continues to challenge existing media balances'. ${ }^{4}$

Depending whom you believe, MNP is about de-siloing marketing functions, it is about neutrality in communications planning, or it is about advertisers responding to the internet. There's a battle for ideas here that is eerily familiar to those schooled in CRM: consultants jostle with each other to re-define the current 'fad' so that it centres on their intellectual product.

Perhaps some in the marketing community are confused. If so, much of this confusion arguably stems from a lack of appreciation of where media sits vis-à-vis communications mix techniques and routes to market in the strategic planning process. Media decisions are seen as sitting alongside segmentation or positioning decisions. This makes no sense. In fact, the media decision should be one of the last planning decisions we take. It's very important - that's not in question - because it involves spending money, and lots of it. But which media to choose is best done once one knows what the firm is good at, what the proposition to the customer is, what market one wishes to go for, how to segment that market and how to position the company against the competition. A decent batting order might be that described in Figure 1.

Once a firm has identified its competitive position, and has created or enhanced its brand, it then has to decide its best route to market. With its ability to physically move goods, direct 
marketing is a channel option. The next planning level is communications mix: of which advertising, PR, sales promotion and direct marketing are a major part. These are often, wrongly, described as media. In fact they are communications techniques. Only once the communications mix is decided is the company properly ready to decide on media.

\section{NEUTRALITY}

The central point of neutrality is that each medium is considered as a potential player, depending on the particular circumstances of the firm, in a particular market, at a particular time: hence media decisions vary depending on the context the company is in. In reality, different sectors often tend to slip into 'media conventions'. In fundraising, for instance, direct mail is often considered best for recruiting long-time givers. Brand builders often automatically assume television is best for building mass appeal. These conventions are important: if MNP means anything, it means 'hang on, are we becoming creatures of habit here, making lazy decisions, and hence missing out on opportunities to choose better media for our situation?'

So, what is needed is a way of judging each medium in terms of what the company faces at the time. Direct marketers are in a better position than advertisers to assess media. In direct marketing, one can compare media with each other while keeping other variables constant. Most importantly, one can confidently link spend (cost per thousand audience) with income (gross margin) to get to the final arbiter of medium: choose the medium with the lowest cost per sale or cost per customer. Individual clients can do this, but the industry as a whole can build up collective wisdom that can be shared. One 'wisdom' is that in direct marketing no one medium dominates (as yet). If one did, everyone would be using it and there would be no need to have this debate.

\section{AIMRITE - A WAY OF CHOOSING MEDIA}

The rest of this paper introduces a framework, AIMRITE, designed to answer the key question: 'for a particular situation, how can we judge which media we should put into test?'

Each of AIMRITE's components is explained in more detail in Figure 2 (To illustrate each point, and to show how the whole model works together, imagine that a new cinema is being opened in, say, Bristol - a city of some 500,000 people in the South West of England. This theatre will show 'alternative', independent films away from the Hollywood mainstream. The launch will include a special offer for the first few shows that will encourage responses that can be used to build a prospects database.)

\section{Audience}

The first, and usually most important, variable is audience. Media choices are heavily influenced by the way the target audience is defined. Lifestyle groupings may lend themselves well to magazine adverts, or maybe direct mail via 'lifestyle' lists while geographic targeting lends itself to door drops. Target audiences can be tightly or loosely defined, and can be defined according to different descriptors. Target audiences that are tightly defined can be addressed by more precise media. The most well known audience is usually a firm's existing customers, while at the other end of the scale, there are suspects - a broad category of people fitting the target description, but with no known 


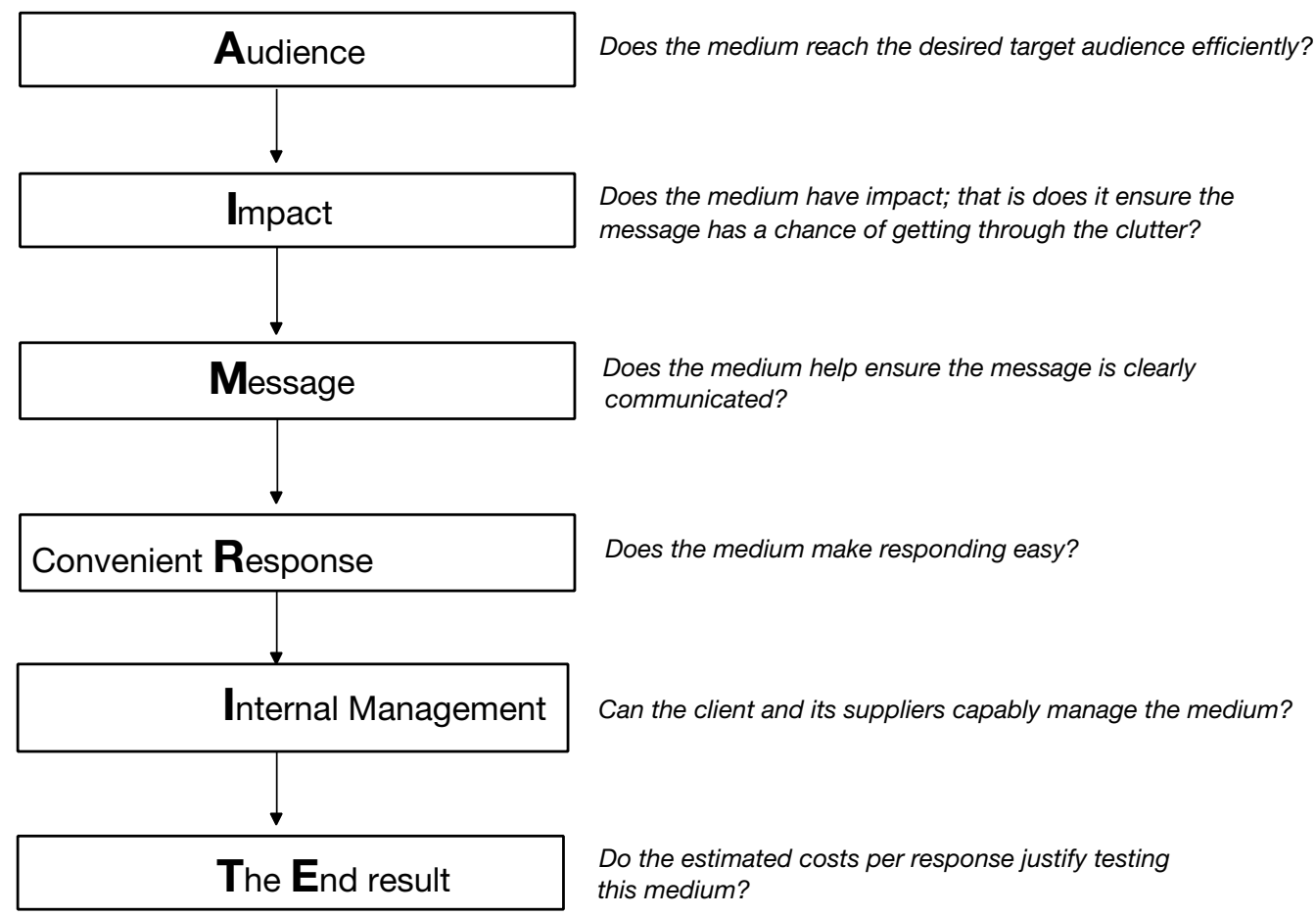

Figure 2: AIMRITE - A framework for judging media

prior contact with the company. These would be approached through very different media.

In Figure 3 the principle - broadscale media for broad audiences, precise media for precise audiences - is well understood, but new technology threatens the old order. Key new technology media include e-mail and SMS; both are capable of precise targeting (though both are still very immature industries). Conventional media have tended to the rule that, the more precise they are, the more they cost per thousand contacts. Both e-mail and SMS are capable of high volume, low cost per thousand deployment, but also with high precision. Both these media therefore bring mass customised one-to-one communication one step closer - in theory. In practice, 'cowboy' users and poor practice are significant threats to both these media. (This is also true of the fixed line telephone in the UK. Recent poor practice using fixed line outbound telemarketing has led to well over 3 million people signing up to the telephone privacy service (TPS) run by the Direct Marketing Association (DMA)).

One final 'audience' factor to consider is the inbuilt 'media responsiveness' of the target market. Media responsiveness is the natural predisposition of some people to prefer to do business through one particular medium. One charity with an aged donor audience never uses the telephone to communicate: its donors prefer a letter. The internet will clearly be a strong medium for those comfortable with it, while others will never use it.

\section{Impact}

There are two dimensions to media impact. The first is the extent to which the media can cut through the 'noise' of a crowded commercial world. E-mail, 


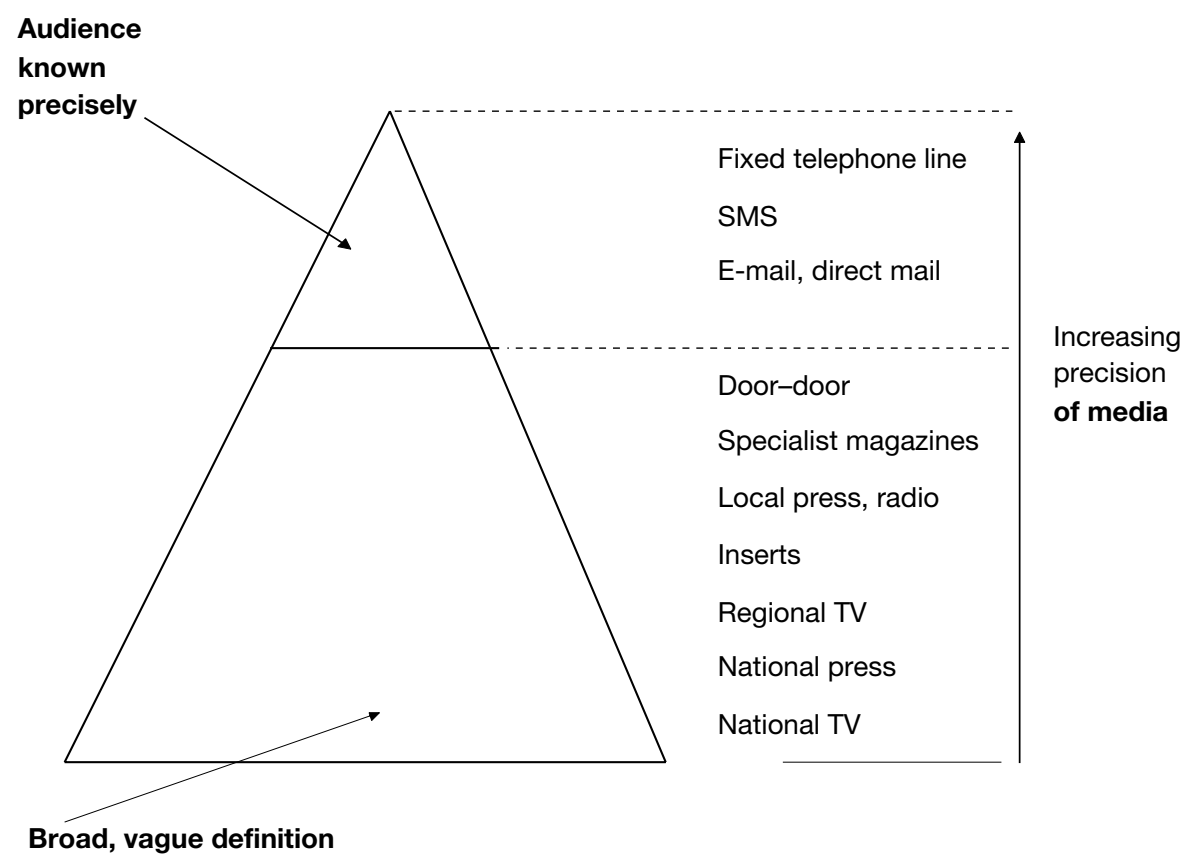

Figure 3: Media choice according to target audience definition

SMS, mail and land line telephones all reach the audience directly. The telephone, in particular, has huge impact, which, sadly, is so poorly deployed in practice. Direct mail is also losing its power through overuse: Direct Mail Information Service (DMIS) reports that the proportion of mail opened has dropped from over 80 per cent to just over 60 per cent in the last ten years.
The second impact dimension is summed up by Marshall McCluhan's phrase: 'The medium is the message.' For motorcyclists in the UK, the magazine Ride has a strong brand identity. Here, the medium, in a sense, creates a halo effect around the adverts it carries. Just the fact that a company has advertised in Ride carries a message to the reader: 'we are a serious, biker-focused advertiser.

\section{Illustrative example - launching a new 'independent' cinema in Bristol}

The target audience definition is broad and vague - in many ways a typical broadscale media definition. The future customers will live mostly in Bristol, one hour's drive from the cinema, be aged 18-55 but biased to 18-35; social class AB bias; but attitudinally less mainstream, more bohemian.

This immediately suggests media that economically are best suited to covering Bristol as a mass audience. It also hints at more precise media that could be aimed at lists of 'bohemian' profiles in Bristol. At this stage one could pencil in local press, inserts, radio, local leisure magazines and door-door marketing. Direct mail, telephone/mobile and e-mail look less credible thanks to the imprecision of audience definition. Geodemographic identification of bohemian areas within the geographic boundary could make door-door an early favourite with perhaps the best audience fit. 


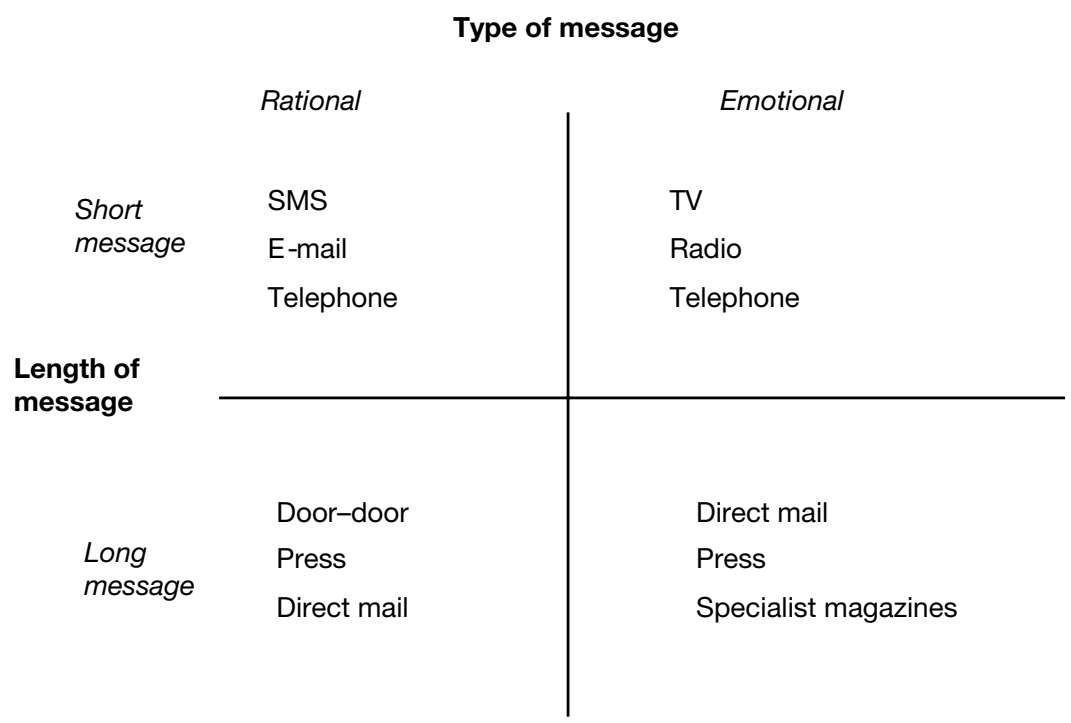

Figure 4: Choosing medium according to type and length

McCluhan's principle works for individual titles — The Financial Times versus The Sun - and for the media themselves. To advertise on television confers legitimacy on the brand - it is an announcement that the company is big, public. Television also creates word of mouth more powerfully than any other medium, (though mostly for brand build rather than direct response adverts).

\section{Message}

Once the prospect's attention has been obtained, the media must then help you to get across the necessary information in a persuasive manner. Television is a compelling medium for inspiring an emotional response, because of its sound and vision qualities. Direct mail, on the other hand, is good for imparting large volumes of information about complex products like, say, financial services. Thus, to get the best match of medium and message, both the volume and type of the information we want to impart should be considered. This is illustrated in Figure 4.

Direct marketers have traditionally been masters of the rational message,

\section{Bristol cinema - impact}

Media impact is important to the new cinema. Competition for leisure time is intense and media 'noise' competing for the leisure pound is deafening. For all that, impact should not take primacy over audience fit, which is the primary economic driver of media choice. Television would have huge impact for a message about a new cinema, but the audience fit isn't close enough.

Local magazines with Time Out style listings would have obvious media synergy and lift the impact of any marketing spend. Local radio also has impact - broadcast media advertisements often have an element of pizzazz and energy created. Meanwhile, direct mail/door-door has a different sort of impact, in that these media have a higher chance of being noticed. 


\section{Bristol cinema - message}

'Our new independent cinema provides you with a great alternative night out'. There are some factual aspects to this message, but lots of emotional benefits that must be communicated. There are some brand building, symbolic messages there too. So, a medium that can best bring these out is needed. Television is ideal in many ways, but once again audience considerations take precedence. Two or more media could be considered here to do the rational/emotional messages in two parts. Creative radio could convey emotion, with the local Time Out (called Venue), supporting this but adding factual stuff about the location and first film shown. Door drops also fit well here: plenty of space for all kinds of messages and creative scope for film photography and so on.

selling product unique selling points, making offers, promising benefits. More recently, with the expansion of direct marketing as a delivery strategy within sectors such as motoring, tourism and and sport, more emotional messages with brand symbolism at the forefront are being communicated by direct marketing. With the expansion of this 'brand response', emotionally strong media such as television arguably should see significant growth from direct marketing budgets. However, the emotional power of great copy should not be forgotten - this author can remember press adverts for Amnesty International that had a sensational impact on the reader.

\section{Response convenience}

This has nothing to do with the size of the response. This factor is concerned with how much effort is required to respond to different media. This is very important in impulse purchase markets, where response will drop once the 'moment' is lost. Certain media are much easier to respond to than others: outdoor media such as posters are more difficult for consumers to respond to than, say, e-mail. A well known saying among practitioners is 'time kills response'. The ideal response medium is one, then, which makes the act of telephoning, text responding, e-mailing or responding to a web site, as easy and quick as possible. People are more likely to respond from the comfort of their own home, at a time when there is nothing else going on to distract them, and when very little effort is required. The telephone and e-mail are top of the direct marketing media league for convenience, while coupon usage has dropped dramatically.

\section{Bristol cinema - response convenience}

Not such a vital factor as audience, impact or message. That said, cinema is sometimes an impulse purchase, so some consideration of this variable is needed. The most response-convenient media, the telephone/mobile and e-mail, have, for the time being been ruled out by the imprecise audience definition. Of those media still in play, radio and Venue magazine are less easy to respond to than door drops, which can include a phone number and easily be posted to a notice board. 


\section{Internal management}

Imagine a newcomer to direct marketing who decides to place direct response adverts in the local press and a local magazine. This newcomer would no doubt be rather surprised to find that while the press ad could slot in later that week, the magazine had a lead time of four months. This story highlights the need to carefully understand those management issues. For instance, the best medium for testing different creative approaches may be direct mail. Press ads may have the shortest lead time if one is in a hurry. Door-drops may be relatively easier to manage than direct mail in the absence of experience and the need to run the campaign oneself without outside help.

\section{Bristol cinema - Internal management}

The management team at the cinema has a fairly modest budget and little experience. It will be looking for help from outside agencies, but may want to consider media that are easier to manage. Local press is relatively straightforward, while direct mail offers rather more complications.

\section{The end result}

All of the issues to consider before making that final choice in favour of a short list of media to test, have now been pulled together. These initial considerations are an attempt to whittle down the media to those which will get the best end result. At this final stage, the focus is on those media which it is believed will give the highest possible response at lowest cost.

There is a general rule that those media which elicit a higher response also tend to be the most expensive. For example, although telephone responses are potentially the highest of any media, the costs per thousand contacts are also the highest. As a result a cost/response model can be generated which offers a rough guide to marketers.

Sometimes, in a particular sector, extensive testing reveals a medium which outperforms other media for all competitors in that area. Traditional direct marketers will know that china collectibles tend to sell best using Sunday supplement press advertising, while charities often use direct mail to recruit possible donors 'cold'. However, when totaling up all marketing activity, the average cost of getting one response is roughly similar across all media.

So what is the 'average cost' of getting one response? Here one enters a very dangerous area, because response will always depend on the specific business situation; a well thought out offer, good timing, incentives and so on. There is, therefore, a huge variation around the mean response rate for a medium, even within one industry sector. A major player in the loans sector of financial services reckons on different campaigns delivering costs per response varying from $\mathcal{K}^{12}$ to over $£ 600$, with an average campaign costing $\mathcal{E} 250$ to generate one response. These figures illustrate the dangers of generalisation by just quoting the average. Nevertheless, some practical 'rules of thumb' could be developed, because these can be useful for media planning in the absence of more specific data. 'Official' figures are hard to come by for many media, but there is a source of data for direct mail. The DMIS surveys of companies using mail for acquisition has found average response rates of about 1 per cent. If the average cost per thousand is typically about $\mathcal{E} 500$ per thousand mailers, then 1 per cent per response gives a cost per response of ${ }^{5} 50$. Using the collective 
Table 1: Comparison of media costs and typical relative response rates

\begin{tabular}{lll}
\hline Medium & $\begin{array}{l}\text { Approx. cost per } \\
\text { thousand }(\boldsymbol{\Sigma})\end{array}$ & $\begin{array}{l}\text { Example responses to acquistion } \\
\text { programmes }\end{array}$ \\
\hline Direct mail & 500 & $1 \%$ \\
SMS & 30 & between low and 2\% \\
E-mail & $5-20$ & between low and $2 \%$ \\
Press & $4-20$ & $0.01-0.1 \%$ \\
Magazines & $10-50$ & $0.02-0.5 \%$ \\
Inserts & $40-70$ & $0.1-1.0 \%$ \\
Household delivery (door-door)? & $40-250$ & $0.1-2.0 \%$ \\
Direct response: TV & $7-15$ & $0.01-0.08 \%$ \\
Direct response: radio & 2 & $0.005 \%$ \\
Telemarketing outbound & 6,000 & $10 \%$ (NB to existing customers) \\
\hline
\end{tabular}

experience of direct marketers over many media, and over many years, one can say that it typically costs about $£, 30-70$ to obtain one response in an acquisition programme.

Table 1 compares costs per thousand audience reach and typical average responses. Note the potential of e-mail and SMS to re-write the economics of media - but will these media really deliver the $2+$ per cent that some believe? Perhaps they are better suited as retention media.

\section{Bristol cinema - The end result}

The AIMRITE model provides a short list of media to test. The cinema could test the following:

- Venue magazine + local radio

- Venue magazine + door drops

- Local radio + door drops

\section{CONCLUSION}

'Media neutral planning' is a phrase that has been much bandied about in the last year or two, but there's little evidence of widespread good practice in choosing media objectively. Too often firms are content to be creatures of habit, missing out on chances to differentiate themselves through a consistent, objective reassessment of media choices.

Direct marketers can take a lead role in professional MNP. The ability of direct marketers to precisely link costs with incomes and to scientifically compare these figures in media testing implies a logical, left brain approach to media decision making.

This paper introduces the AIMRITE model as a vehicle that can help to take some essential qualitative decisions prior to crunching the numbers. There is plenty of room for effective, emotional factors to be taken into account. AIMRITE provides a marketer with a clear pathway to become aware of all the factors impacting on the media decision, and to then weigh them up accordingly. It is hoped that this paper helps in a small way to clarify the MNP debate.

\section{References}

1 CIM (2004) available at http://www.cim.co.uk/cim/ser/html/cover.cfm.

2 Available at http://www.shapetheagenda.com.

3 Cree, R. (2002) 'A breed apart', Director, Vol. 55, No. 11, pp. 68-71.

4 Available at www.iabuk.net. Accessed March 2004. 